\title{
The ICT role in the world economy: an input-output analysis
}

\author{
Elvio Mattioli ${ }^{1,2}$, Giuseppe Ricciardo Lamonica ${ }^{1,2, ~ *}$ \\ ${ }^{1}$ Department of Economic and Social Sciences, Faculty of Economics "G.Fuà", Ancona, Italy \\ ${ }^{2}$ Università Politecnica delle Marche, Ancona, Italy
}

\section{Email address:}

e.mattioli@univpm.it(E. Mattioli),g.ricciardo@univpm.it(G. R. Lamonica)

\section{To cite this article:}

Elvio Mattioli, Giuseppe Ricciardo Lamonica. The ICT Role in the Word Economy: An Input-Output Analysis. Journal of World Economic Research. Vol. 2, No. 2, 2013, pp. 20-25. doi: 10.11648/j.jwer.20130202.11

\begin{abstract}
As a long series of empirical studies have shown, the ICT (Information and Communication Technologies) sector has acquired a crucially important role in the economies of the most industrialized nations. In this context, the purpose of the paper is quantitatively to assess the economic structure of ICT using the world input-output table. For each of the 35 sectors of activity shown in the table, two indices were computed: backward linkage (power of dispersion) to assess global vertical integration; and forward linkage (sensitivity dispersion) to assess horizontal integration. Several features of these indices were found in order to categorize the sectors most connected with ICT.
\end{abstract}

Keywords: Input-Output Models, Information and Communication Technologies, Key Sector, Backward Linkage, Forward Linkage, Inter Industry Dependencies

\section{Introduction}

The international economic situation has undergone profound changes in the past few years which can be related in part to the market globalization process, and in part to the global economic crisis of the past decade.

In this context, the strategic role played by the Information and Communication Technologies sector (ICT) continues to strengthen in national economies, especially those of the most industrialized countries. This sector has recorded, and continues to record, extremely enviable growth rates, $[1,5]$.

Suffice it to consider that global production by the ICT sector at the end of the 1970s was 215 billion dollars, and that twenty years later it had reached 2,234 billion dollars, which is equal to approximately $8 \%$ of global GDP, and enough to overtake production in the oil and automobile sectors. See [6].

The ICT sector, which consists of all companies producing electronic and digital technology for the transfer of information, knowledge and innovation, currently represents a supporting and driving force for national economies [7]. It is in constant evolution, albeit with different dynamics, is very far from reaching its saturation point, and can condition the lifestyles of individuals, the labour market and economic development [8,9].
Because the strategic position which the sector has attained is such that it would be impossible to contemplate a modern society without ICT products, the purpose of this study is to analyse the role played by this sector by measuring the relations which tie it to the other productive sectors, focusing on the economic systems of the most important world countries.

To this end, this inquiry uses the sectorial interdependence tables (Input-Output tables) originally conceived by Leontief [10]. The I-O table provides information on the flows of goods and services between the economic sectors of a country over a given time period, and it represents one of the most important tools for analyzing the economic structure of a country. It is for this reason that the Input-Output table is particularly suited to the purposes of this paper [11, 19].

The data used are taken from the World Input-Output Database, a project funded by the European Commission as part of the 7th Framework Programme, Theme 8: Socio-Economic Sciences and Humanities.

The database covers 27 European countries and 13 other major countries in the world for the period from 1995 to 2009, and it is downloadable at the following web site address: http://www.wiod.org/database/index.htm.

Referring for details to [20], the World Input-Output Table (WIOT) is an extension of the national Input-Output 
Table (IOT). Indeed, the difference respect to the national tables is that the use of products is broken down according to their origins. Each product is produced either by a domestic industry (sector) or by a foreign industry (sector) and unlike the national IOT, this information is made explicit in the WIOT.

The World Input-Output Table used in this analysis is related to 2009, built at current prices with a classification for 35 industries. According to the OECD definition, see [21], the ICT sector coincides with the 30th industry of the WIOT.

To assess the position occupied by the ICT sector in the economic system of the set considered, several different methods can be used. See for example [22, 30]. Among these, the Rasmussen approach has become an accepted technique with which to identify key sectors in an economy [31], and it is consequently one of the most frequently used in analyses of this type. See for example $[32,36]$.

The inverse Leontief matrix (henceforth $\mathrm{L}$ ) is the core of the Rasmussen approach. Let $\mathrm{x}_{\mathrm{ij}}$ be the flow of goods from the $\mathrm{i}$-th to the $\mathrm{j}$-th sector, and let $\mathrm{X}_{\mathrm{j}}$ be the total production of the $\mathrm{j}$-th sector. Then, $\mathrm{a}_{\mathrm{ij}}=\mathrm{x}_{\mathrm{ij}} / \mathrm{X}_{\mathrm{j}}$, which bears the name 'technical coefficient' or 'direct input coefficient', shows how many units of production of the i-th sector are required by the $\mathrm{j}$-th sector in order to obtain one monetary unit of production.

Moreover, if $\mathrm{A}$ is the matrix whose elements are the technical coefficients, then $\mathrm{L}=(\mathrm{I}-\mathrm{A})^{-1}$ is the matrix commonly called the "Leontief inverse".

The generic $1_{i j}$ element of $\mathrm{L}$ measures the total requirement, both direct and indirect, of goods and services (henceforth "total requirements" or "multiplier") produced by the i-th industry which are necessary in order to satisfy one unit of final uses of the $\mathrm{j}$-th sector. In other words, it measures the extent to which a unit increase in the final demand of the $\mathrm{j}$-th sector causes a production increase in the $\mathrm{i}$-th sector.

Consequently the $\mathrm{j}$-th column-sum of $\mathrm{L}$ measures the total requirements needed by the $\mathrm{j}$-th sector in order to produce one unit of final uses of its production; or, the extent to which a one unit increase in the final demand of the $\mathrm{j}$-th sector causes production increases in all sectors:

$$
1 \mathrm{~L}_{\mathrm{j}}
$$

where 1 is a vector of one, a prime (') denotes a row vector, and $\mathrm{L}_{\mathrm{j} j}$ is the $\mathrm{j}$-th column of the $\mathrm{L}$. On the contrary, the row-sum of the L matrix:

$$
\mathbf{L}_{\mathrm{i} .}^{\prime} \mathbf{1}
$$

measures the total production requirements of the i-th sector needed to off-set a unitary increase in final uses of each product. In other words, the magnitude of output increases in the i-th sector if final demand of all sectors increases by one unit.

Dividing (1) and (2) by the total number of sectors (n) yields the mean requirement (or the mean production increase) of the $\mathrm{j}$-th sector $\left(1^{\prime} \mathrm{L}_{\mathrm{j}} / \mathrm{n}\right)$ and the mean requirement supplied by the $i$-th sector $\left(\mathbf{L}_{i}^{\prime}, 1 / n\right)$.

Alternatively, (1) is the mean impact on the economic system's production caused by a one unit increase in the final demand of the $\mathrm{j}$-th sector, and (2) is the mean impact on the i-th sector caused by a one unit increase in the final demand of all sectors.

For the purposes of comparison, these two means are normalized with the general mean of all the elements in L:

$$
\begin{gathered}
\beta_{j}=\frac{\mathbf{1}^{\prime} \mathbf{L}_{. j} / \mathrm{n}}{\mathbf{1}^{\prime} \mathbf{L} \mathbf{1} / \mathrm{n}^{2}} \quad \text { for } \mathrm{j}=1, . ., \mathrm{n} \\
\varphi_{\mathrm{i}}=\frac{\mathbf{L}_{\mathrm{i} .}^{\prime} \mathbf{1} / \mathrm{n}}{\mathbf{1}^{\prime} \mathbf{L} \mathbf{1} / \mathrm{n}^{2}} \quad \text { for } \mathrm{i}=1, . ., \mathrm{n}
\end{gathered}
$$

The index (3), known as 'Backward linkage' (or power of dispersion), measures the degree of activation of an economic sector: the more this is greater than 1, the more the sector is important for the economy of the country considered, because it requires a production level by the other sectors in excess of the general mean. By contrast, the more the index falls below 1, the less important is the sector considered.

The other index, which is known as 'Forward linkage' (or sensitivity of dispersion), measures the level at which the output of one sector is used as input to the remaining productive sectors. It thus measures the degree of reaction of an economic sector.

In this case, too, the more the index is greater than 1, the more important the corresponding sector is because it supplies its production to the others sectors at a level which exceeds the general mean. By contrast, the more the index falls below 1, the less important is the sector considered.

Joint analysis of these two indices makes it possible to determine how an individual sector is woven into the economic structure of a country and how important it is. Generally, if:

- $\quad \beta_{\mathrm{i}}<1$ and $\varphi_{\mathrm{i}}<1$, the sector is an "Independent or island sector"; it acquires and sells out production less than the mean;

- $\quad \beta_{\mathrm{i}} \geq 1$ and $\varphi_{\mathrm{i}}<1$, the sector is a "Driver sector"; it acquires production from the other sectors above the mean but transfers their production below the mean;

- $\quad \beta_{\mathrm{i}}<1$ and $\varphi_{\mathrm{i}} \geq 1$, the sector is a "Strategic sector", i.e. a sector with output oriented to the economic system;

- $\quad \beta_{\mathrm{i}} \geq 1$ and $\varphi_{\mathrm{i}} \geq 1$, the sector is a "Key sector"; it acquires and transfers production above the mean.

Unfortunately, see [37], the forward linkage does not provide a measure symmetrical with that provided by backward linkage. The assumption that final demand for all sectors increases by one unit is misleading since not all sectors are of equal importance in the structure of demand.

With a large input-output table, a small sector (j) which relies heavily on sector (i) for input will lead to a biased 
index of forward linkage for sector (i).

Capacity expansion in sector (i) based on high forward linkage may therefore have a disappointing impact on the economy's overall rate of growth, because of the small size of sector $(\mathrm{j})$.

Various proposals have been made to overcome this problem. See in particular $[38,42]$. Since in the literature the discussion is still open, and this is not the place to examine all of it, this survey considers the solution, now generally accepted, see [37], that starts from the B matrix, where elements are the direct output coefficients $\left(a_{i j}=x_{i j} / X_{j}\right)$, and utilizes the Ghosh inverse matrix: that is, $\mathrm{B}^{*}=(\mathrm{I}-\mathrm{B})^{-1}$.

The generic element of this matrix $\left(b_{i j}^{*}\right)$ represents the increase in total output of the $\mathrm{j}$-th industry in response to a one unit increase in added value of the $\mathrm{i}$-th sector. Thus the forward index is determined in the following manner:

$$
\varphi_{\mathrm{i}}^{*}=\frac{\mathbf{B}_{\mathrm{i} .}^{* \prime} \mathbf{1} / \mathrm{n}}{\mathbf{1}^{\prime} \mathbf{B}^{*} \mathbf{1} / \mathrm{n}^{2}}
$$

where $B_{i .}^{* \prime}$ is the $i$-th row of $B^{*}$ matrix.

This new measure of forward linkage is quite different from the previous one. It is a normalized measure of the output increments of a sector if, ceteris paribus, the added value of the other sectors changes by one unit.

Indices (3) and (5) are averages and hence sensitive to extreme values. For example, a sector with high forward linkages could sell large amounts of output to only a few sectors. To account for extreme values, the coefficient of variation of the column and row entries respectively of the $\mathrm{L}$ and $\mathrm{B}^{*}$ matrices can be usefully employed:

$$
\begin{aligned}
& V\left(\beta_{j}\right)=\frac{\sqrt{\sum_{i=1}^{n}\left(1_{i j}-\sum_{i=1}^{n} 1_{i j} / n\right)^{2} /(n-1)}}{\sum_{i=1}^{n} 1_{i j} / n} \\
& V\left(\varphi_{i}^{*}\right)=\frac{\sqrt{\sum_{j=1}^{n}\left(b_{i j}^{*}-\sum_{j=1}^{n} b_{i j}^{*} / n\right)^{2} /(n-1)}}{\sum_{j=1}^{n} b_{i j}^{*} / n}
\end{aligned}
$$

The lower these coefficients are for a specific sector, the more evenly that sector's input purchases and output sales are dispersed among the different sectors of the economy.

The rest of the paper is structured as follows. The second and third sections focus on the ICT sector, considering respectively its direct and global impact on the economies of the set considered. The final section draws the conclusions.

\section{Analysis of Direct Relations of the ICT Sector}

The weight of the ICT sector in the set considered is illustrated in Table 1 of the Appendix. Firstly, in column (h) of Table 1, the weight of the sector is in mean $7.27 \%$ of the country's total production (or total output).

Belgium (13.37\%), France (13.14\%) and Great Britain $(12.57 \%)$ are the countries in which the sector has the greatest impact.

On the other hand, Indonesia (1.18\%), Bulgaria (1.81\%), Taiwan $(2.67 \%)$ and China (2.99\%) are the countries where the incidence is more limited. In the remaining countries, however, the weight stands at around $7.36 \%$ with a standard deviation equal to 2.25 .

On analysing the rows of the world Input-Output table, or with regard to the output allocation, it emerges that in mean $66.01 \%$ of the sector's total production is destined for intermediate use, $19.10 \%$ for final use, and $14.89 \%$ is exported.

In particular, column (b) of Table 1 shows that, on the one hand Australia (80.99\%) is the country with the highest percentage of output absorbed by non-ICT sectors (intended for other productive sectors), and on the other, that Indonesia $(0.41 \%)$ is the country with the lowest percentage. However, the sector's production in most of the countries $(90.24 \%)$ is primarily destined for intermediate use. This means that the sector can be considered, in general, an intermediate sector.

Excluding Indonesia on the one hand, and Ireland, Luxembourg, Malta and the Czech Republic on the other, an average of $18.50 \%$ of the industry output is destined to final uses.

In particular, most of the countries (63\%), column (c) of Table 1, have a percentage of final consumption between $10 \%$ and $20 \%$, while only for 10 countries is this percentage between $20 \%$ and $50 \%$.

Finally, see column (d) of Table 1, India is the country with the highest percentage of production exported, while Turkey, Russia and Japan are the countries with the lowest percentages. However, $80.5 \%$ of the countries in the set considered have an export percentage not exceeding $20 \%$ of the sector's total production, and $71.1 \%$ of the countries have a percentage between $20 \%$ and $50 \%$.

Inspection of the World Input-Output Table from the input viewpoint (along the columns) shows that, in mean, $43.15 \%$ of the production cost of the ICT industry can be attributed to NON-ICT sectors - column (e) of Table 1. This percentage increases to $58.78 \%$ for China, but falls to $26.63 \%$ for Mexico, and stands at around $42.22 \%$ for the remaining countries.

In general, $83 \%$ of the countries have a percentage of intermediate input not exceeding $50 \%$ of the total input. Consequently, ICT can be considered a sector with a high added value that is, in mean, $56 \%$ of the total production column (g) of Table 1. Mexico (72.53\%) is the country with 
the highest percentage, and China (40.72) is the country with the lowest percentage.

Put very briefly, it emerges quite clearly that the ICT sector plays a particularly important role in the countries analyzed. Its production is mostly destined for intermediate uses, and it is a sector with high added value.

\section{Analysis of Indirect Relations of the ICT Sector}

Table 2 of the Appendix reports the values assumed by the indices measuring global integration on the sales side (forward) and the purchases side (backward) of the ICT sector. These have also been classified according to the position occupied in the economic system of each country, and according to whether they exceed the quartiles $\left(\mathrm{Q}_{0.25}\right.$, $\mathrm{Q}_{0.50}$, and $\mathrm{Q}_{0.75}$ ) of the two indices.

Some interesting statistical regularities are apparent. Firstly, the backward index assumes values lower than those of the forward index. Consequently, the sector is more integrated on the sales side than it is on the purchases? side.

By contrast, the forward index is less variable than the backward index. However, the values of the two variability indices, except in rare cases, assume quite low values.

With the exception of India and Indonesia, the forward index has a value greater than unity (above the average level). Instead, with the exception of China, Czech Republic and Romania, the backward index has values less than one (below the average level).

Thus the ICT sector can be considered, in general, a strategic sector, i.e. one integrated on the sales side but weakly connected on the purchases side. Only in China and Czech Republic is the ICT a key sector, while in Indonesia and India it is an independent sector i.e. weakly connected on the buy and sell sides.

Considering the position occupied in their respective economic systems, it is possible to note that the backward index never exceeds the median value, and that for $49 \%$ of the countries it is less than the first quartile. By contrast the forward index always assumes values above the median, and for $76 \%$ of cases it is greater than the third quartile.

It is very clear that, in the world scenario, the ICT sector does not have an important position on the buys side because the degree of activation imposed on the other sectors is not particularly high, and in general is below the average value.

Instead important is the position of the sector on the sales side; or, in other words, the degree of activation received by the sector from all the other sectors. This latter is always a value above the mean, and in many countries it is one of the highest values.

In conclusion, it is quite clear from the survey that the ICT sector has an important role in the economies of the countries concerned. It is a sector with high added value, and it makes a major contribution to the formation of GDP.
This confirms the key position occupied by the sector.

The results also show that the ICT is important as a supplier to the other economic sectors. By contrast, it has modest importance as a demander, i.e. as a low driving role, or a low ability to expand the production of an economic system.

\section{Conclusion}

The paper has analyzed the role of the ICT sector in the economic systems of the most industrialized countries, the purpose being to assess the position played by the sector by measuring the relations which tie it to the other productive sectors.

As reported by a large number of studies, this sector has not only achieved an important position in the economic systems of many countries, especially the most developed ones, but it is also exceptionally dynamic and has a multiplier effect on the other economic sectors.

The novelty of this study consists of two aspects. The first is that it takes account not only of the direct links, as is normal in the literature, but also of the indirect effects between ICT and economic sectors, quantitatively measuring their impact.

The second is that the study has conducted its analysis and developed indicators taking into comprehensive account also the spatial links among the economies of 40 countries.

The analysis has been carried out using the World Input Output Table developed by the European Commission. The table covers 27 European countries and 13 other major countries in the world for the period from 1995 to 2009. The one used in this analysis is related to 2009.

To assess the sector's degree of integration, the Rasmussen forward and backward linkage indices have been considered. The former measures the integration of a sector from the sales side, and the second from the purchases side. This two indices measure the relative importance of a sector as supplier to the other sectors and its relative importance as demander.

We are aware of the limitations of these two indices, but also that the debate is still open and that the methodological alternatives proposed have not yet received unanimous consensus. Consequently, the Rasmussen approach continues to be widely used in empirical analyses.

In general, the results have highlighted the homogeneous behaviour of the ICT sector in all of the economic systems considered.

In particular, our calculations on the ICT sector deepen and generalize those already reported in the literature. ICT has almost a significant weight in the economies of the set considered, even surpassing some traditional industrial sectors. Moreover, it is a sector with high added value, closely integrated on the sales side but very little so on the purchases side. The indices measuring global integration calculated in the paper highlight that ICT has a strategic position in the economic scenario of the countries analyzed. 


\section{Appendix}

Table 1. Descriptive analysis of the ICT sector from WIOT year 2009

\begin{tabular}{|c|c|c|c|c|c|c|c|c|}
\hline Countries & (a) & (b) & (c) & (d) & (e) & (f) & (g) & (h) \\
\hline Australia & 84,46 & 30,99 & 15,14 & 0,40 & 50,55 & 4,98 & 47,92 & 10,28 \\
\hline Austria &, 57 & & 16,30 & 2,13 & & 7,86 & & \\
\hline Belgium & 84,17 & 8,59 & 13,46 & 2,38 & 49,98 & 9,47 & 46,98 & 13,37 \\
\hline Bulgaria & $t, 11$ & 5,51 & 14,46 & 1,44 & 31,08 & 5,49 & 57,35 & 1,81 \\
\hline Brazil & 60,20 & 57,23 & 39,48 & 0,33 & 35,64 & 2,45 & & 5,76 \\
\hline Canada & 83,41 & 73,70 & 15,11 & 1,48 & 37,94 & 4,02 & 1,07 & 5,64 \\
\hline China & 86,84 & 69,41 & 11,81 & 1,36 & 58,78 & 7,54 & 0,72 & 2,99 \\
\hline Cyprus & 83,36 & 76,41 & 15,71 & 0,93 & 32,82 & 4,75 & 66,19 & 5,57 \\
\hline Czech Rep. & 90,14 & 78,10 & 7,81 & 2,05 & 55,88 & 9,32 & 42,39 & 7,88 \\
\hline Denmark & 85,82 & 77,51 & 13,05 & 1,13 & 32,03 & 2,73 & & 10,68 \\
\hline Germany & 84,07 & 73,05 & 14,59 & 1,34 & 48,43 & 7,76 & 41 & 10,02 \\
\hline Spain & 76,72 & 50 & 21,87 & 1,41 & 42,69 & 4,68 & & 7,08 \\
\hline Est & 87,10 & 70,07 & 10,23 & 2,67 & 41,27 & 9,90 & & 8,34 \\
\hline Finland & 84,00 & 62,47 & 10,89 & 5,11 & 41,47 & 9,23 & 34 & 7,48 \\
\hline Frar & 80,99 & 75, & 18,57 & 0,44 & 43,67 & 3,77 & & 13,14 \\
\hline Gre & 87,80 & 72 & 10,63 & 1,57 & 32,37 & 4,29 & & 12,57 \\
\hline Gre & 79,51 & 72,70 & 19,58 & 0,91 & 48,87 & 16,37 & 46,81 & 4,45 \\
\hline Hur & 84,62 & 61 , & 12 & 2,83 & 41,99 & 13,17 & & 7,53 \\
\hline & & & & & & & & \\
\hline Indis & 49,67 & 28 & 40,83 & 9,50 & 30,48 & 4,66 & & 3,78 \\
\hline & 8 & & 3,22 & 8,93 & 51,17 & & & 10,71 \\
\hline & & & & & & & & \\
\hline Japan & 4 & 79 & 19,38 & 0,08 & 49,43 & 0,91 & & 8,26 \\
\hline Korea & 8 & 78 & 11,33 & 0,79 & 36,94 & 4,03 & & 3,94 \\
\hline & & & 23 & 1,26 & & & & \\
\hline Lux & 85,87 & 52 & 4,27 & 9,86 & 44,69 & 22,12 & & 8,15 \\
\hline Latvia & 83,90 & 79,14 & 11,92 & 4,17 & 44,04 & 6,66 & 92 & 7,33 \\
\hline & & & & 7 & & & & 5,05 \\
\hline Mal & ,96 & & & 2,30 & 43,15 & & & 8,27 \\
\hline Netherlands & 79,02 & 55,41 & 18,15 & 2,83 & 40,45 & 10,98 & 92 & 11,46 \\
\hline Poland & 77,09 & & 21,19 & 1,73 & 41,00 & 7,87 & & 5,65 \\
\hline Port & 82,59 & & 16,62 & 0,78 & 50,46 & 6,19 & 4 & 7,80 \\
\hline Romania & 85,65 & 69,21 & 12,84 & 1,52 & 51,74 & 10,58 & 46,07 & 5,51 \\
\hline Rus & & & 41,23 & 0,04 & 39,00 & 1,68 & & 6,08 \\
\hline & 79,60 & 67 & 17,57 & 2,83 & 44,37 & 8,99 & & 6,47 \\
\hline Slor & 81,96 & 73 & 16,58 & 1,46 & 43,49 & 8,15 & 44 & 8,49 \\
\hline Swe & 82,99 & & 14,21 & 2,80 & 43,63 & 9,26 & & 10,71 \\
\hline & & & 21,37 & 0,03 & 33,22 & 4,69 & 64,87 & 3,94 \\
\hline Taiwan & 84,31 & 72,63 & 14,72 & 0,97 & 47,64 & 11,22 & 51,31 & 2,67 \\
\hline US & 79,31 & & 20,19 & 0,50 & 33,69 & 1,99 & & 11,57 \\
\hline Rest of world & 65,04 & 47,69 & 33,52 & 1,44 & 47,47 & 9,67 & 52,53 & 4,80 \\
\hline
\end{tabular}

Legend:

(a) \% of ICT total output intended for intermediate consumption;

(b) $\%$ of ICT total output intended for internal intermediate consumption;

(c) $\%$ of ICT total output intended for internal final use;

(d) $\%$ of ICT total output exported for final use;

(e) $\%$ of intermediate input on total ICT input;

(f) $\%$ of intermediate imported input on total ICT input;

(g) $\%$ of added value on total ICT input;

(h) $\%$ of ICT total output on total output of country .

Table 2. Backward and forward indices values of the ICT sector

\begin{tabular}{lcccccc}
\hline Countries & $\beta \mathrm{i}$ & $\begin{array}{c}\beta \mathrm{i} \\
\text { Pos. }\end{array}$ & $\varphi_{\mathrm{i}}^{*}$ & $\begin{array}{c}\varphi_{\mathrm{i}}^{*} \\
\text { Pos. }\end{array}$ & $\mathrm{V}(\beta \mathrm{i})$ & $\mathrm{V}\left(\varphi_{\mathrm{i}}^{*}\right)$ \\
\hline Australia & $0,95(25)$ & $\mathrm{B}$ & $1,35(3)$ & $\mathrm{D}$ & 17,55 & 24,63 \\
Austria & $0,87(27)$ & $\mathrm{A}$ & $1,34(6)$ & $\mathrm{D}$ & 16,71 & 25,66 \\
Belgium & $0,95(27)$ & $\mathrm{A}$ & $1,44(4)$ & $\mathrm{D}$ & 17,40 & 26,31 \\
Bulgaria & $0,80(33)$ & $\mathrm{A}$ & $1,38(5)$ & $\mathrm{D}$ & 14,23 & 23,78 \\
Brail & $0,80(26)$ & A & $1,04(17)$ & $\mathrm{C}$ & 18,58 & 24,01 \\
Canada & $0,79(26)$ & $\mathrm{B}$ & $1,22(6)$ & $\mathrm{D}$ & 16,67 & 25,32
\end{tabular}

\begin{tabular}{lcccccc} 
China & $1,24(19)$ & $\mathrm{B}$ & $1,51(12)$ & $\mathrm{D}$ & 13,29 & 15,96 \\
Cyprus & $0,74(30)$ & $\mathrm{A}$ & $1,18(7)$ & $\mathrm{D}$ & 17,73 & 27,70 \\
Czech Rep. & $1,07(23)$ & $\mathrm{B}$ & $1,49(4)$ & $\mathrm{D}$ & 15,92 & 21,68 \\
Denmark & $0,72(31)$ & $\mathrm{A}$ & $1,36(3)$ & $\mathrm{D}$ & 16,33 & 30,49 \\
Germany & $0,91(24)$ & $\mathrm{B}$ & $1,28(6)$ & $\mathrm{D}$ & 17,86 & 24,82 \\
Spain & $0,88(28)$ & $\mathrm{A}$ & $1,24(10)$ & $\mathrm{C}$ & 16,62 & 23,20 \\
Estonia & $0,86(29)$ & $\mathrm{A}$ & $1,44(4)$ & $\mathrm{D}$ & 14,72 & 24,31 \\
Finland & $0,87(30)$ & $\mathrm{A}$ & $1,36(7)$ & $\mathrm{D}$ & 14,93 & 23,19 \\
France & $0,86(27)$ & $\mathrm{A}$ & $1,32(4)$ & $\mathrm{D}$ & 18,10 & 27,46 \\
Great Britain & $0,73(32)$ & $\mathrm{A}$ & $1,34(4)$ & $\mathrm{D}$ & 16,72 & 29,99 \\
Greece & $0,87(18)$ & $\mathrm{B}$ & $1,13(4)$ & $\mathrm{D}$ & 19,03 & 24,53 \\
Hungary & $0,86(30)$ & $\mathrm{A}$ & $1,34(3)$ & $\mathrm{D}$ & 15,10 & 23,40 \\
Indonesia & $0,88(27)$ & $\mathrm{B}$ & $0,51(32)$ & $\mathrm{A}$ & 34,82 & 20,57 \\
India & $0,73(24)$ & $\mathrm{B}$ & $0,93(19)$ & $\mathrm{B}$ & 21,65 & 27,59 \\
Ireland & $0,93(26)$ & $\mathrm{B}$ & $1,40(3)$ & $\mathrm{D}$ & 14,30 & 21,65 \\
Italy & $0,88(28)$ & $\mathrm{A}$ & $1,35(3)$ & $\mathrm{D}$ & 16,70 & 25,35 \\
Japan & $0,92(23)$ & $\mathrm{B}$ & $1,28(10)$ & $\mathrm{C}$ & 17,98 & 24,82 \\
Korea & $0,87(29)$ & $\mathrm{A}$ & $1,47(10)$ & $\mathrm{C}$ & 13,29 & 21,62 \\
Lithuania & $0,76(29)$ & $\mathrm{A}$ & $1,22(4)$ & $\mathrm{D}$ & 16,84 & 26,75 \\
Luxembourg & $0,89(24)$ & $\mathrm{B}$ & $1,47(4)$ & $\mathrm{D}$ & 13,77 & 22,29 \\
Latvia & $0,90(27)$ & $\mathrm{B}$ & $1,37(7)$ & $\mathrm{D}$ & 16,21 & 24,37 \\
Mexico & $0,70(28)$ & $\mathrm{B}$ & $1,09(6)$ & $\mathrm{D}$ & 17,81 & 27,55 \\
Malta & $0,92(27)$ & $\mathrm{B}$ & $1,50(2)$ & $\mathrm{D}$ & 13,41 & 21,70 \\
Netherlands & $0,84(31)$ & $\mathrm{A}$ & $1,28(4)$ & $\mathrm{D}$ & 16,41 & 25,10 \\
Poland & $0,87(30)$ & $\mathrm{A}$ & $1,27(6)$ & $\mathrm{D}$ & 16,03 & 23,28 \\
Portugal & $0,94(24)$ & $\mathrm{B}$ & $1,32(6)$ & $\mathrm{D}$ & 17,59 & 24,61 \\
Romania & $1,00(22)$ & $\mathrm{B}$ & $1,37(5)$ & $\mathrm{D}$ & 17,32 & 23,29 \\
Russia & $0,82(27)$ & $\mathrm{B}$ & $1,13(17)$ & $\mathrm{C}$ & 20,28 & 27,71 \\
Slovakia & $0,91(24)$ & $\mathrm{B}$ & $1,33(6)$ & $\mathrm{D}$ & 16,26 & 23,81 \\
Slovenia & $0,90(28)$ & $\mathrm{A}$ & $1,29(5)$ & $\mathrm{D}$ & 16,70 & 23,75 \\
Sweden & $0,88(23)$ & $\mathrm{B}$ & $1,33(7)$ & $\mathrm{D}$ & 15,70 & 23,73 \\
Turkey & $0,79(28)$ & $\mathrm{A}$ & $1,15(10)$ & $\mathrm{C}$ & 17,29 & 24,79 \\
Taiwan & $0,92(22)$ & $\mathrm{B}$ & $1,43(9)$ & $\mathrm{C}$ & 13,75 & 20,66 \\
USA & $0,75(28)$ & $\mathrm{A}$ & $1,15(9)$ & $\mathrm{D}$ & 18,69 & 28,16 \\
Rest of world & $0,96(23)$ & $\mathrm{B}$ & $1,08(11)$ & $\mathrm{C}$ & 18,30 & 20,57 \\
\hline & & & & & & \\
& & &
\end{tabular}

In parentheses the rank occupied by the sector in the economic system of the country.

$A=$ Index $\leq Q_{0.25} ; B=Q_{0.25}<$ Index $\leq Q_{0.5} ; C=Q_{0.5}<$ Index $\leq Q_{0.75} ; D=$ Index $\geq Q_{0.75}$

\section{References}

[1] Beardsell, M., and Henderson, V. (1999). Spatial evolution of the computer industry in the USA. European Economic Review 43, 431-456.

[2] Edquist, H. (2005). The Swedish ICT miracle - myth or reality?. Information Economics and Policy, 17, 275-301.

[3] Jorgenson Dale W., Khuong V. (2005). Information Technology and the World Economy. Scand. Journal of Economics 107(4), 631-650.

[4] Pilat, D., and Wölfl, A. (2004). ICT production and ICT use: what role in aggregate productivity growth. In: The Economic Impact of ICT Measurement, Evidence and Implications. OECD, Paris.

[5] Wong, P.K. (2002). ICT production and diffusion in Asia. Information Economics and Policy, 14 (2), 167-187.

[6] Istat (2009) Le tecnologie dell'informazione e della 
comunicazione nelle imprese. Statistiche in breve.

[7] Timmer, M. (2012). The World Input-Output database (WIOD): contents, sources and methods. downloadable at http://www.wiod.org.

[8] Bryan, J., Jones, C., and Munday, M. (2005). Investigating the potential of key sectors using multisectoral qualitative analysis: a Welsh case study. Environment and Planning C, 23, 633-656.

[9] Kraemer, K.L., and Dedrick, J. (2001). Information technology and productivity: results and policy implications of cross-country studies. In: Pohjola, M., (Ed.) Information Technology, Productivity and Economic Growth. Oxford University Press, 257-279.

[10] Leontief, W. (1974). Structure of the world economy: outline of a simple Input-Output formulation. The American Economic Review, 64, 823-834.

[11] Beyers, W.B. (1976). Empirical identification of key sectors: some further evidence, Environment and Planning A, 8, 231-236.

[12] Cella, G. (1984). The input-output measurement of interindustry linkages. Oxford Bulletin of Economics and statistics, 46, 73-84.

[13] Clements, B.J. (1990). On the decomposition and normalization of interindustry linkages. Economic Letters, 33 (4), 337-340.

[14] Dietzenbacher, E. (1992). The Measurement of interindustry linkages. Key Sectors in the Netherlands. Economic Modeling, 9, 419-437.

[15] Guccione, A. (1986). The Input-Output measurement of interindustry linkages: A comment. Oxford Bulletin of Economics and Statistics, 48 (4), 373-377.

[16] Hewings, G. (1982). The empirical identification of key sectors in an economy: a regional perspective. Developing Economies, 20(2),173-195.

[17] McGilvray, J. (1977). Linkages, key-sectors and de-velopment strategy. In Leontief, W., (ed.) Structure, System and Economic Policy, UK, Cambridge University Press, 49-56.

[18] Richardson, H.W. (1972). Input-Output and regional economics. New York, John Wiley \& Son.

[19] Simpson, D., and Tsukui, J. (1965). The fundamental structure of input-output tables, an international comparison. The Review of Economics and Statistics, 47, 434-446.

[20] Van Ark B. (2002). Measuring the new economy: an international comparative perspective. Review of In-come and Wealth 48, 1, 1-14.

[21] OECD, (2000). Measuring the ICT sector. OECD, Paris.

[22] Chenery, H.B. and Watanabe, T. (1958). International comparisons of the structure of production. Econometrica, 26, 487-521.

[23] Dietzenbacher, E. (2002). Interregional multipliers: looking backward, looking forward. Regional Studies, 36, 125-136.
[24] Hirschman, A.O. (1958). The strategy of economic development. New Haven, Conn: Yale University Press.

[25] OECD (2009). Guide to measuring the information society, OECD, Paris.

[26] OECD, (2008). The contribution of the ICT sectors to Economic growth in OECD countries: backward and forward Linkages. OECD, Paris.

[27] Rasmussen, N. (1956). Studies in intersectoral relation. North Holland, Amsterdam.

[28] Schultz, S. (1977). Approaches to identifying key sectors Empirically by means of Input-output analysis. Journal of Development Studies, 14, 77-96.

[29] Sonis, M, Hewings, G., and Guo, J. (2000). A new image of classical key sector analysis: minimum in formation decomposition of the Leontief inverse. Economics System Research, 13(3), 401-423.

[30] Sonis, M., Guilhoto, J.J., Hewings, G.J., and Martins, E.B. (1995). Linkages, key sectors and structural change: some new perspectives. Developing Economies, 33, 233-270.

[31] Morrissey K., and O'Donoghue C. (2013). The role of the marine sector in the Irish national economy: An input-output analysis. Marine Policy, 37, 230-238

[32] Karagiannis, G., and Tzouvelekas, V. (2010). Sectoral linkages and industrial efficiency: a dilemma or a requisition in identifying development priorities?. Annals of Regional Science, 45, 207-233.

[33] Beynon, M.J., and Munday, M. (2008). Stochastic key sector analysis: an application to a regional in- put-output framework. Annals of Regional Science, 42, 863-877.

[34] Alcantara, V., and Padilla, E. (2003). Key sectors in final energy consumption: an input-output application to the Spanish case. Energy Policy, 31, 1673-1678.

[35] Midmore, P., Munday, M., and Roberts, A. (2006). Assessing industry linkages using regional in- put-output tables. Regional Studies, 40, 329-343.

[36] Bulmer, V. T. (1982). Input-output analysis in developing countries. John Wiley, New York.

[37] Hazari, B.R. 1970. Empirical identification of key sectors in the Indian economy. Review of Economics and Statistics, $52,301-305$

[38] Jones, L. P. (1976). The measurement of Hirschmanian Linkages. Quarterly Journal of Economics, 90, 323-333.

[39] Laumas, P. (1976). Key sectors in some underdeveloped countries: A Reply. Kyklos, 29, 767-769.

[40] Miller, R. E., and Blair, P. D. (2009). Input Output analysis foundation and extensions. Cambridge University Press.

[41] Oosterhaven, J. (1988). On the plausibility of the Supply-Driven Input-Output model. Journal of Regional Science, 28, 203-271.

[42] Ghosh, A. (1958). Input-output approach to an allocative system. Economica, 25, 58-64. 